\title{
A Study on the Model of Traffic Flow and Vehicle Exhaust Emission
}

\author{
Han Xue, ${ }^{1}$ Shan Jiang, ${ }^{2}$ and Bin Liang ${ }^{3}$ \\ ${ }^{1}$ Institute of Development Studies, Shougang Corporation, Beijing 100082, China \\ ${ }^{2}$ School of Management and Economics, Beijing Institute of Technology, Beijing 100081, China \\ ${ }^{3}$ Beijing Automotive Research Institute Company Limited, Beijing 100079, China
}

Correspondence should be addressed to Shan Jiang; jiangshanyou@163.com

Received 9 September 2013; Revised 16 November 2013; Accepted 2 December 2013

Academic Editor: Wuhong Wang

Copyright (C) 2013 Han Xue et al. This is an open access article distributed under the Creative Commons Attribution License, which permits unrestricted use, distribution, and reproduction in any medium, provided the original work is properly cited.

\begin{abstract}
The increase of traffic flow in cities causes traffic congestion and accidents as well as air pollution. Traffic problems have attracted the interest of many researchers from the perspective of theory and engineering. In order to provide a simple and practical method for measuring the exhaust emission and assessing the effect of pollution control, a model is based on the relationship between traffic flow and vehicle exhaust emission under a certain level of road capacity constraints. In the proposed model, the hydrocarbons (HC), carbon monoxide $(\mathrm{CO})$, and nitrogen oxides $\left(\mathrm{NO}_{x}\right)$ are considered as the indexes of total exhaust emission, and the speed is used as an intermediate variable. To verify the rationality and practicality of the model, a case study for Beijing, China, is provided in which the effects of taxi fare regulation and the specific vehicle emission reduction policy are analyzed.
\end{abstract}

\section{Introduction}

The negative impact of urban road traffic is mainly on air quality [1], ecosystem, and noise level [2]. Due to the continuing increase of motor vehicles, human health [3] and environment have been severely impacted. According to the classification of air pollutant sources in urban area, motor vehicle emission accounts for more than $80 \%$ of the air pollution in major cities [4]. The statistics of Beijing show that the level of carbon monoxide (CO) and nitrogen oxides $\left(\mathrm{NO}_{x}\right)$ exceeds national standard even in the city's fourth and fifth ring roads where the average speed of vehicles is high.

Since the concept of sustainable development has been adopted into the theory and methods of urban transport systems planning, the coordination between transportation development and urban environment becomes the focus of the urban transportation research in the 21st century. In recent years, many scholars have studied vehicle exhaust emission for environment protection [5].

In order to reduce air pollution caused by motor vehicles, several control measures have been imposed in the last decade including upgradation of gasoline quality, strict environmental standards, and the promotion of new energy vehicles. Schifter et al. studied the trends of exhaust emissions from gasoline motor vehicles in the metropolitan area of Mexico City [6]. They presented results on brand new vehicles which indicated that $\mathrm{NO}_{x}$ emission factors, though they were within the Tier I standard, deteriorated rapidly with the travel distance. Alkurdi et al. determined the profile and concentration of PAH in exhaust emissions of light- and heavy-duty vehicles running on the roads of Damascus city [7].

Ropkins et al. provided a comprehensive critical review of the techniques utilized to monitor real-world vehicle exhaust emissions [8]. Real-world measurements (measurements of exhaust emissions from vehicles in operation on the highway network) differ from laboratory-based measurements (typically using test cycles) because they have a more realistic potential to capture the range of variability typically encountered in real-world driving, including variability in driver behaviour, interactions with other road users, and interactions with highway infrastructure, all of which have the potential to influence exhaust emissions. May et al. used four independent yet complementary approaches to investigate POA gas-particle partitioning [9]: sampling artifact 
correction of quartz filter data, dilution from the constant volume sampler into a portable environmental chamber, heating in a thermodenuder, and thermal desorption/gas chromatography/mass spectrometry analysis of quartz filter samples. This combination of techniques allowed gas-particle partitioning measurements to be made across a wide range of atmospherically relevant conditions. Mikulcic et al. analyzed the influence of different amounts of fuel, mass flow of the tertiary air, and the adiabatic wall condition on the decomposition rate of limestone particles, burnout rate of coal particles, and pollutant emissions of a newly designed cement calciner. Numerical models of calcination process and pulverized coal combustion were developed and implemented into a commercial computational fluid dynamics code, which was then used for the analysis [10].

These studies covered the measurement of vehicle exhaust emission factors $[11,12]$, the analysis or model of pollutant emission on traffic corridors [13], and so forth. However, the required variables and detection methods were complicated, and the conclusions were significant only to the sample. Due to the lack of rapid and effective macrodetection and calculation methods for overall pollution throughout the city roads, these studies cannot provide effective support to traffic regulation departments to develop policies or take interim control measures.

This paper puts forward a vehicle exhaust emission model based on the speed which is taken as an intermediate variable and the exhaust emission of hydrocarbons (HC), carbon monoxide $(\mathrm{CO})$, and nitrogen oxides $\left(\mathrm{NO}_{x}\right)$ as indexes of exhaust emission. This model provides a simple and easy method to measure and effectively control the exhaust emission.

\section{An Analysis of Motor Vehicle Exhaust Emissions}

2.1. Factors of Vehicle Exhaust Emissions. Motor vehicle exhaust emissions are known to contain carbon monoxide (CO), nitrogen oxides $\left(\mathrm{NO}_{x}\right)$, hydrocarbons (HC), suspended particulate matter, and a small amount of sulfur dioxide $\left(\mathrm{SO}_{2}\right)$. Since carbon monoxide $(\mathrm{CO})$, nitrogen oxides $\left(\mathrm{NO}_{x}\right)$, and hydrocarbons $(\mathrm{HC})$ are tested as pollutants by two Chinese national standards, namely, Emission Standard for Exhaust Pollutants from Light-duty Vehicle (GB 14761.193) and Emission Standard for Exhaust Pollutants from Gasoline Engine of Vehicle (GB 14761.2-93); in this paper carbon monoxide $(\mathrm{CO})$, nitrogen oxides $\left(\mathrm{NO}_{x}\right)$, and hydrocarbons (HC) are selected as assessment indexes of road traffic exhaust emissions.

The emission factor is a key parameter in the calculation of vehicle pollutant emission, which is also called emission of unit mass, and it is the average emission under the influence of various factors according to the Chinese national standard, namely, Automotive Emission-Terms and Definitions (GB5181-2001). Vehicle exhaust emission is affected by many factors, including the features of vehicles (such as vehicle type, technical level, emission control devices, and operation condition), urban road conditions, maintenance frequency, fuel type, the levels and effect of maintenance, and the characteristics of roads (altitude, temperature and humidity, road conditions, and traffic conditions). The motor vehicle operation conditions are different between urban roads and highways. The former conform to the standard conditions while the latter conform to the constant speed condition. The differences between two emission factors for different operation conditions are relatively large, so it is necessary to consider the average speed of vehicles for the calculation of vehicle emission factors.

2.2. The Selection of Testing Routes and Testing Method. The selection of testing routes was a result of consideration of the features of Beijing traffic network. Representative types of roads were chosen for testing, including the Second Ring Road, the Third Ring Road, the Fourth Ring Road, the Fifth Ring Road, the Changan Avenue, and the Jingtong Expressway. Testing time covered morning and evening rush hours as well as nonrush hour daytime period. Motorists' driving habits were also considered.

The main device for vehicle exhaust emission testing was the SEMTECHDS gas analysis system made by the Sensor Company, USA. Five automotive brands were selected as testing vehicles due to their higher market share, including Volkswagen, Honda, GM, Ford, and Nissan. GPS speedometer and slope meter auxiliary equipment were used for continuous record of each vehicle's speed and road conditions. Data were collected for ten hours of steady driving without accidents for each vehicle under testing. Vehicle's exhaust emissions were measured under the operation speed: $0 \mathrm{~km} / \mathrm{h} \sim 90 \mathrm{~km} / \mathrm{h}$. The impact caused by the installation position of testing device on vehicles was eliminated.

\section{Speed and Pollutant Emission Model}

Researchers such as Richard Anthony Margiotta believed that emission factors were sensitive to the vehicle speed and their relation function could be expressed as $\mathrm{EF}_{j k}=g(u)[14]$.

3.1. The Relationship between the Pollutant and Vehicle Speed. In order to quantify the relationship between the vehicle speed and the vehicle pollutant exhaust, the impacts of slope, sudden acceleration, and deceleration were eliminated first. That is, the data of vehicles operated at constant speeds on smooth roads were studied first. The method of data collection generated noise fluctuations in data. Therefore, high frequency of noise components was removed through curve-fitting techniques [15]. By comparing the continuous data recorded by kilometers with the corresponding time of SEMTECHDS gaseous analysis system, the exhaust emissions at each time and the corresponding data can be obtained. Figures 1, 2, and 3 reveal the relation curve between the vehicle speeds and the emission factors of $\mathrm{CH}, \mathrm{CO}$, and $\mathrm{NO}_{x}$, respectively.

From Figure 1 to Figure 3, we can see that the trend of comprehensive emission factors of $\mathrm{HC}, \mathrm{CO}$, and $\mathrm{NO}_{x}$ is changing with the mean vehicle speed. There are several points worth noticing. 
TABLE 1: Interval division of acceleration.

\begin{tabular}{|c|c|c|c|c|c|}
\hline \multicolumn{2}{|c|}{ Slowdown } & \multicolumn{2}{|c|}{ Constant speed } & \multicolumn{2}{|c|}{ speedup } \\
\hline Interval index & $\begin{array}{c}\text { Interval range } \\
\left(\mathrm{m} / \mathrm{s}^{2}\right)\end{array}$ & Interval index & $\begin{array}{l}\text { Interval range } \\
\left(\mathrm{m} / \mathrm{s}^{2}\right)\end{array}$ & Interval index & $\begin{array}{l}\text { Interval range } \\
\left(\mathrm{m} / \mathrm{s}^{2}\right)\end{array}$ \\
\hline$N_{1}$ & $-0.3<a \leq-0.1$ & 0 & $-0.1<a \leq 0.1$ & $P_{1}$ & $0.1<a \leq 0.3$ \\
\hline $\mathrm{N}_{2}$ & $-0.6<a \leq-0.3$ & & & $P_{2}$ & $0.3<a \leq 0.6$ \\
\hline$N_{3}$ & $-1.0<a \leq-0.6$ & & & $P_{3}$ & $0.6<a \leq 1.0$ \\
\hline$N_{4}$ & $a \leq-1.0$ & & & $P_{4}$ & $a>1.0$ \\
\hline
\end{tabular}

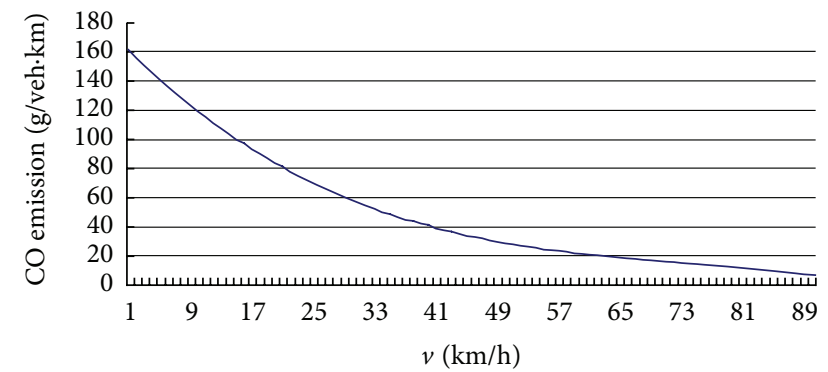

FIGURE 1: The change curve of CO comprehensive emission factor.

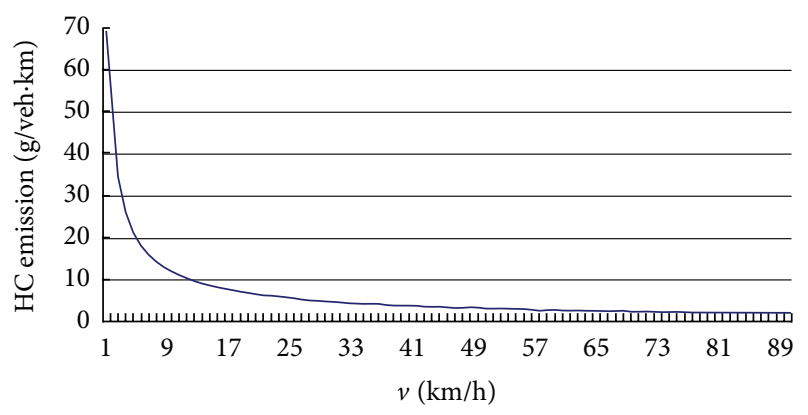

FIGURE 2: The change curve of $\mathrm{CH}$ comprehensive emission factor.

Firstly, along with the increase of mean vehicle speed, vehicle emission of $\mathrm{CH}$ comprehensive factor decreases. Secondly, along with the increase of mean vehicle speed, vehicle emission of CO comprehensive factor gradually decreases. Thirdly, along with the increase of the mean vehicle speed, comprehensive $\mathrm{NO}_{x}$ emission factor decreases at first and then increases gradually, with $50 \mathrm{~km} / \mathrm{h}$ and $60 \mathrm{~km} / \mathrm{h}$ being the minimum value.

3.2. The Relationship between the Acceleration and Exhaust Emissions. As shown in Table 1, the vehicle running state could be divided into eight kinds according to the acceleration frequency under all kinds of driving conditions.

In addition, the authors selected speed ranges in the condition of low speed, medium speed, and high speed to analyze the relationship between the acceleration and exhaust emissions in order to eliminate the impact of the speed. The division of speed range is as follows: low speed was defined as within the interval $(10,20] \mathrm{h} / \mathrm{km}$, medium speed as within the interval $(40,50] \mathrm{h} / \mathrm{km}$, and high speed as within the interval

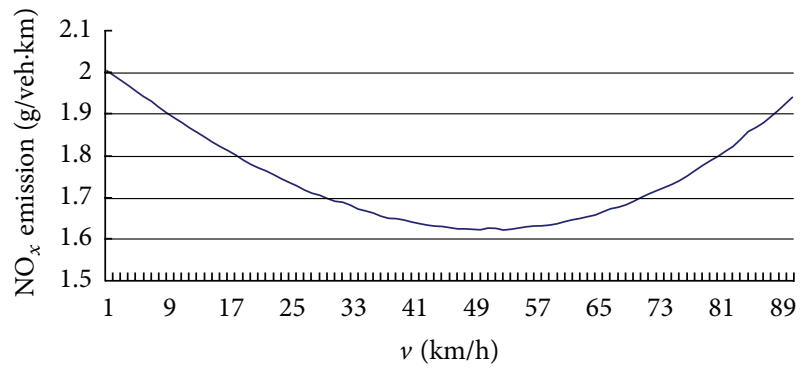

FIGURE 3: The change curve of $\mathrm{NO}_{x}$ comprehensive emission factor.

$(60,70] \mathrm{h} / \mathrm{km}$. In each speed range, the authors analyzed the relationship between the acceleration and exhaust emissions.

The data show that $\mathrm{HC}, \mathrm{CO}, \mathrm{NO}_{x}$, and $\mathrm{CO}_{2}$ emission factors increase quickly with the increasing acceleration, especially in the range of high speed. When $a<-0.6 \mathrm{~m} / \mathrm{s}^{2}$ (a denotes acceleration), the amplitude of emission factors increases slowly with increasing acceleration; when $-0.6<$ $a \leq 0.3 \mathrm{~m} / \mathrm{s}^{2}$, the amplitude of emission factor increases rapidly with the increasing acceleration; when $0.3<a \leq$ $1.0 \mathrm{~m} / \mathrm{s}^{2}$, the amplitude of emission factor decreases rapidly with the increasing acceleration; when $a>1 \mathrm{~m} / \mathrm{s}^{2}$, the amplitude of emission factor increases with the increasing acceleration.

\subsection{Fitting and Correction of the Speed and Exhaust Emission} Function. In addition to the speed and acceleration, the vehicle exhaust emission is also closely related to the slope of road. Therefore, vehicle specific power (VSP) was introduced to fit exhaust emission curve.

VSP was put forward by Palacios and Luis and applied to analyze remote sensing data [16]. VSP is one of the parameters most close to the actual conditions, and it has been one of the core parameters of the next generation mobile emission model. $P_{\mathrm{VPS}}$ denotes the ratio of the motor vehicle output power and its quality (in $\mathrm{kW} / \mathrm{t}$ ). $P_{\mathrm{VPS}}$ combines parameters such as speed, acceleration, slope, and wind resistance, so it can greatly improve the accuracy of the fitting.

$V$ denotes speed, $a$ denotes acceleration, and $\theta$ denotes a road gradient expressed in radians, and the following functions are obtained:

$$
\begin{gathered}
E_{\mathrm{NO}_{x}}=2.0164+[1.1 a+9.81(a \tan (\sin \theta))-0.0142] V \\
+0.0001 V^{2}+0.00000053 V^{3}
\end{gathered}
$$




$$
\begin{aligned}
E_{\mathrm{CO}}= & 167.154+[1.1 a+9.81(a \tan (\sin \theta))-5.2911] V \\
& +0.0662 V^{2}+0.0003 V^{3}, \\
E_{\mathrm{HC}}= & 68.7252 V^{1.1 a+9.81(a \tan (\sin \theta))-0.7760} .
\end{aligned}
$$

Thus, the basic functional relationship between exhaust emission and speed has been obtained. In order to more accurately reflect the actual urban road conditions of Beijing, the authors calculated the mean value of VSP for many types of motor vehicles. If the accurate VSP of a particular type of vehicle is to be obtained, more samples are needed to correct the specific parameters.

\section{Speed and Traffic Flow Model}

4.1. Traffic Features Analysis. Urban roads are the main infrastructure of urban transportation. Urban roads should not only satisfy the requirement of the traffic but also meet the requirement of urban land [17]. Features of urban road traffic are related to urban road grade and urban area. In general, urban road traffic at different levels has different features. The composition of urban road traffic is complicated. Generally, urban road traffic covers all sorts of motor vehicles, and the ratio of motor vehicles is related to the road grades and urban area. The traffic flow is normally distributed to time. If the influence of road intersections is not considered, vehicle's speed on main lines is mainly related to the traffic flow. In this paper, the research was conducted in Beijing area. Since the main lines in Beijing are the city's ring roads and there are no traffic lights on these ring roads, consideration of the influence of the intersections is not needed.

4.2. The Relationship between Speed and Traffic Flow. Based on the Greenshields model, the function of the relationship between speed and flow can be obtained as follows:

$$
\bar{U}_{i}=N_{i} K_{j}\left(v-\frac{v^{2}}{\bar{v}}\right) .
$$

Here $\bar{U}_{i}$ denotes the standard traffic flow through road $i$ per unit time, $\mathrm{pcu} / \mathrm{h} ; N_{i}$ denotes the number of lanes on road $i$; $K_{i}$ denotes the traffic density of road $i, \mathrm{pcu} / \mathrm{km} ; v$ denotes the average speed on road $i, \mathrm{~km} / \mathrm{h} ; \bar{v}$ denotes the free flow speed of road $i, \mathrm{~km} / \mathrm{h}$.

Therefore, when the traffic flow is in a steady state, the function of the relationship between speed and traffic flow can be obtained from the above function as follows:

$$
v=f\left(U_{i}\right)=\bar{v}\left(\frac{1}{2} \pm \sqrt{\frac{1}{4}-\frac{\bar{U}_{i}}{N_{i} \bar{v} K_{j}}}\right) .
$$

4.3. Discussion. As for transportation system which has reached a balance between supply and demand [18], traffic density and the relationship between vehicle speed and traffic flow will change while adding new traffic flow into traffic system (Figure 4). In AB area, as vehicle traffic flow is smooth,

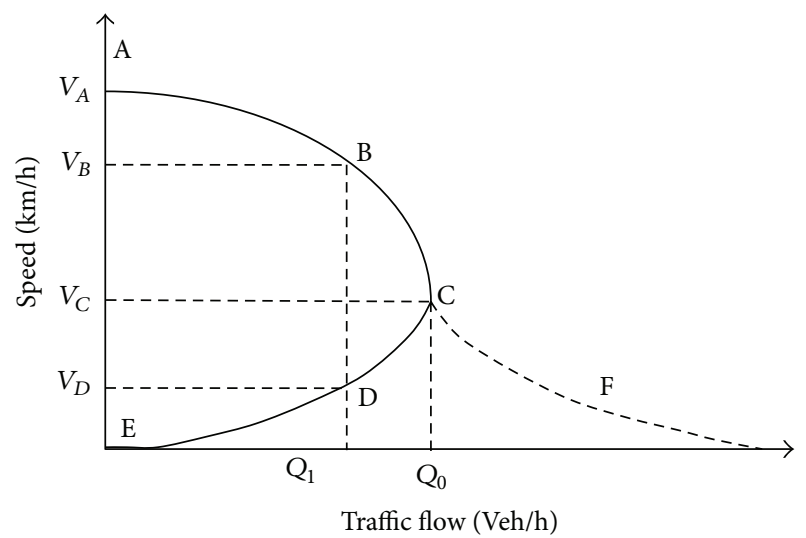

Figure 4: The relationship between speed and traffic flow.

vehicle's speed is always of highest level. With new vehicles entering into the transportation system, the density of traffic flow increases and enters into BC area. Gradually, traffic density increases with the spaces among vehicles reduced; Interference among vehicles increases and as a result vehicles' speed declines. As new vehicles continue to enter into the transportation system, the volume of vehicles increases and so does the traffic density until the road eventually becomes saturated. When $q_{c}=Q$, the transportation system is in the state of saturation $[19,20]$. At this time, if timely effective measures are not taken to restrict new cars from entering into the system, the speed and traffic flow will fall further, and road traffic efficiency continues to decrease. Eventually, serious traffic congestion will happen, transportation system will be paralyzed, and traffic flow will drop to zero.

From the above analysis, it can be seen that, for a given traffic flow $Q_{1},\left(Q_{1}<Q_{0}\right)$, there will be two corresponding speeds $V_{B}$ and $V_{D}$. Thus, in the following case of Beijing traffic where $Q=Q_{1}\left(Q_{1}<Q_{0}\right)$ is given, it can be concluded that $V=V_{D}$, as Beijing's road is very congested.

Formula (3) yields that

$$
v=f\left(U_{i}\right)=\bar{v}\left(\frac{1}{2}-\sqrt{\frac{1}{4}-\frac{\bar{U}_{i}}{N_{i} \bar{v} K_{j}}}\right) .
$$

\section{The Model of Traffic Flow and Vehicle Exhaust Emission}

If $E_{k}=E_{k}(v)$, thus $E_{k}=E_{k}\left(f\left(U_{i}\right)\right)$ from $v=f\left(U_{i}\right)$. Therefore, the model of traffic flow and vehicle exhaust emission is obtained.

In this model, carbon monoxide (CO), nitrogen oxides $\left(\mathrm{NO}_{x}\right)$, and hydrocarbons $(\mathrm{CH})$ are selected as three final indexes for vehicle exhaust emission evaluation. Based on the relationship between vehicle speed and vehicle exhaust emission factors, a mathematical model of total emission and road speed is established. And based on the relationship between speed and traffic flow under a certain level of road capacity, the mathematical model of speed and traffic flow is established. Then, with speed as an intermediate variable a model is established to describe the relationship between 
traffic flow and vehicle exhaust emissions under certain level of urban road capacity constraints. Although the model is based on a single road, as long as the speed of vehicles remains the same on the section road network or the entire road network, the model still applies. Thus, this model provides a theoretical basis to measure the exhaust emission within a certain region and effectively to control them.

\section{Case Study}

Based on the proposed model, with the given road capacity and given traffic volume (through a standard equivalent conversion), road vehicle exhaust emissions ( $\mathrm{CO}, \mathrm{HC}$, and $\mathrm{NO}_{x}$ ) can be analyzed for urban transportation planning and environmental impact assessment.

6.1. Background. Statistics of Beijing Municipal Bureau show that, by the end of 2012, there are 5.2 million motor vehicles in Beijing, while taxis in Beijing are about 66,000, accounting for a very small proportion. However, taxis in Beijing are exempt from the city's vehicle restriction based on the last digit on the license plate and they spend much longer hours on the road than other vehicles every day; their high level of utilization on the road and exhaust emissions have been severely criticized by people. Therefore, based on this model taxi exhaust emissions in Beijing are analyzed.

6.2. The Equivalent Conversion for Taxis and Private Cars. According to the data of the Beijing Transportation Research Center, at present, the average kilometrage of private cars is $15,000 \mathrm{~km}$ per year while a taxi's kilometrage reached 90,000 kilometers, which indicates that a taxi is equivalent to six standard private cars based on kilometrage. In addition, as $40 \%$ kilometrage of private cars is spent for weekend and holiday vacation travels and is spent out of the city's Sixth Ring Road, that is, out of the urban area of Beijing, the ratio of road utilization is $1: 10$ between taxis and private cars within the Sixth Ring Road area, that is, the urban area of Beijing.

According to "the hearing of dynamic adjustment mechanism on Beijing's taxi rents adjustment and the fuel surcharge improvement" the empty-loaded rate of taxis in Beijing was about $31 \%$ in 2012, which means for an average taxi in Beijing in $31 \%$ of the time when it was running on the streets there was no customer. Because of this, the efficiency of taxis is much lower than that of private cars. Taxi meter record data and the cost survey from Beijing Municipal Development and Reform Commission also show that taxi service efficiency is only about $70 \%$ of that of private motor vehicles.

Combining the input and output together, the authors concluded that the ratio of urban road utilization between taxies and private cars within the Sixth Ring Road is about $1: 14$. Therefore, the actual pollution effect of the 66,000 taxis in Beijing is equivalent to that of 924,000 standard private cars.

The data from Beijing Bureau of Statistics showed that there were 5.2 million vehicles in Beijing by the end of 2012, and the private cars were 4.16 million. Due to the vehicle restriction based on the last digit on the license plate in
Beijing, only 3.32 million vehicles are allowed to travel per day. In addition, $80 \%$ of these 3.32 million vehicles are mostly running within the Sixth Ring Road while almost all the taxis are running in the same area. Thus, the actual ratio of road utilization between taxis and private vehicles is 92.4:265, namely, 1:2.9; that is, among every four cars running in the streets in Beijing, at least one is a taxi. According to the model proposed in this paper, it can be deduced that a quarter of vehicle exhaust emissions are discharged by taxis. Given that private vehicles are mostly used for commuting to work, the proportion of the exhaust emissions of taxi is much higher during noncommuting hours.

6.3. The Taxi Planning. According to statistics, the monthly income of an average taxi in Beijing is about 16,300 Yuan, and the kilometrage is $7480 \mathrm{~km}$. Taking the standard of New York City as reference, the daily kilometrage of taxi is $113 \mathrm{~km}$; the present kilometrage of taxi in Beijing could be reduced by $55 \%$. At the same time, in order to ensure the income of taxi drivers, the flag-fall price should increase by $100 \%$, reaching 20 Yuan. According to the price elasticity of taxi demand in Beijing, the number of people using taxi will be reduced by $30 \%$. Meanwhile, due to the wide application of the taxi reservation program, the empty-loaded rate of taxi can be controlled below 10\%. Therefore, the standard equivalent quantity ratio of the taxis and private vehicles will be increased from $1: 14$ to $1: 5$. At this point, the 66,000 taxis are equivalent to 330,000 average private vehicles. The number of average vehicles within the Sixth Ring Road area is reduced to 2.6 million, which is a decrease of $27 \%$.

6.4. The Planning Effect. According to the model, if the volume of vehicles is reduced by $27 \%$, the speed of vehicles in the whole road network can be improved by $24 \%$, while the average commuting time can be reduced by $19.4 \%$. This conclusion is in accordance with the statistical data which show that; by a decrease of $12 \%$ in vehicle volume, the speed of vehicles in the whole road network can be increased by $10 \%$ in Beijing.

Furthermore, according to calculations, the exhaust emissions will be dropped as follows:

$$
\begin{aligned}
& E_{\mathrm{NO}_{x}} \text { emissions will be reduced by } 29.3 \% \text {; } \\
& E_{\mathrm{CO}} \text { emissions will be reduced by } 42.2 \% \text {; } \\
& E_{\mathrm{HC}} \text { emissions will be reduced by } 40.9 \% \text {. }
\end{aligned}
$$

\section{Conclusions}

The objective of this paper is to find the relationship between vehicle exhaust emission and traffic flow under a certain level of urban road capacity constraints. The authors used speed as a bridge to describe the relationship between the two variables and established a model accordingly. The case analysis presented in the paper is to simulate the situation of taxi fare regulation in Beijing, of which the authors deduce the knock-on effects and calculate the city's vehicle exhaust emission reductions. In short, it is obvious that the impact of traffic flow on vehicle exhaust emission can be measured in 
China's congested cities. Therefore the model is an effective way to control the volume of vehicles on urban roads and improve the speed and efficiency of vehicles to reduce the excessive pollution caused by vehicle emission in China.

Limitations and improvements of this model of traffic flow and vehicle exhaust emission include the following. (i) If more accurate results are required, a larger sample is required to calculate the parameters of different models to simulate actual road conditions, because emission performance of different vehicles is different (the types and ages of different vehicles determine different parameters), and (ii) in Beijing, the political center of China, traffic control based on political reasons is taken frequently and causes traffic speeds to reduce drastically or even to zero. Due to this considerable impact, the vehicle speed is too low to fit the curve, as the emissions of vehicles increased sharply. Therefore, in order to make the results more accurate, the stagnant traffic flow (speed of $10 \mathrm{~km} / \mathrm{h}$ or less) should be taken into account into the model, and (iii) exhaust gas contains 150 to 200 different compounds. In addition to carbon monoxide, hydrocarbons, and nitrogen oxide compounds, particulate matter (PM) measured as either PM10 or PM2.5 (i.e., PM less than $10 \mu \mathrm{m}$ or $2.5 \mu \mathrm{m}$ in diameter, resp.) is also quite harmful to human body. PM is a mixture of liquid and solid particles of different sizes and chemicals that varies in composition both spatially and temporally. Epidemiological studies spanning five continents have demonstrated an association between mortality and morbidity and daily, multiday, or long-term (a period of more than a year) exposure to concentrations of pollutants, including PM. The estimated mortality impacts are likely to occur predominantly among elderly people with preexisting cardiovascular and respiratory disease and among infants. It is necessary to put PM emission into model detection range, thereby increasing the credibility of the model in the future.

\section{References}

[1] P. Kumar, M. Ketzel, S. Vardoulakis, L. Pirjola, and R. Britter, "Dynamics and dispersion modelling of nanoparticles from road traffic in the urban atmospheric environment-a review," Journal of Aerosol Science, vol. 42, no. 9, pp. 580-603, 2011.

[2] D. I. Popescu, R. E. Tuns, and I. F. Moholea, "The urban acoustic environment-a survey for road traffic noise," Carpathian Journal of Earth and Environmental Sciences, vol. 6, no. 1, pp. 285-292, 2011.

[3] M. L. Burr, G. Karani, B. Davies, B. A. Holmes, and K. L. Williams, "Effects on respiratory health of a reduction in air pollution from vehicle exhaust emissions," Occupational and Environmental Medicine, vol. 61, no. 3, pp. 212-218, 2004.

[4] G. A. Rhys-Tyler, W. Legassick, and M. C. Bell, "The significance of vehicle emissions standards for levels of exhaust pollution from light vehicles in an urban area," Atmospheric Environment, vol. 45, no. 19, pp. 3286-3293, 2011.

[5] K. Yi, L. Z. Wang, B. X. Qi, L. M. Zhang, and S. Lei, "Investigation and analysis of motor vehicle exhaust emission in cities," Energy Conversion and Application, vol. 1-2, pp. 250-253, 2001.

[6] I. Schifter, L. Díaz, S. Avalos et al., "Trends of exhaust emissions from gasoline motor vehicles in the metropolitan area of Mexico city," International Journal of Environment and Pollution, vol. 21, no. 2, pp. 166-174, 2004.
[7] F. Alkurdi, F. Karabet, and M. Dimashki, "Characterization, concentrations and emission rates of polycyclic aromatic hydrocarbons in the exhaust emissions from in-service vehicles in Damascus," Atmospheric Research, vol. 120-121, pp. 68-77, 2013.

[8] K. Ropkins, J. Beebe, H. Li et al., "Real-world vehicle exhaust emissions monitoring: review and critical discussion," Critical Reviews in Environmental Science and Technology, vol. 39, no. 2, pp. 79-152, 2009.

[9] A. A. May, A. A. Presto, C. J. Hennigan, N. T. Nguyen, and T. D. Gordon, "Gas-particle partitioning of primary organic aerosol emissions: (1) gasoline vehicle exhaust," Atmospheric Environment, vol. 77, pp. 128-139, 2013.

[10] H. Mikulcic, E. von Berg, M. Vujanovic, P. Priesching, and R. Tatschl, "Numerical analysis of cement calciner fuel efficiency and pollutant emissions," Clean Technologies and Environmental Policy, vol. 15, no. 3, pp. 489-499, 2013.

[11] C. R. Fulper, S. Kishan, R. W. Baldauf et al., "Methods of characterizing the distribution of exhaust emissions from lightduty, gasoline-powered motor vehicles in the US fleet," Journal of the Air and Waste Management Association, vol. 60, no. 11, pp. 1376-1387, 2010.

[12] M. M. Baum, J. A. Moss, S. H. Pastel, and G. A. Poskrebyshev, "Hydrogen cyanide exhaust emissions from in-use motor vehicles," Environmental Science and Technology, vol. 41, no. 3, pp. 857-862, 2007.

[13] X. H. Tu, F. Z. Dong, Q. Feng, Y. J. Zhang, and W. Q. Liu, “Onroad remote sensing of $\mathrm{CO}$ and $\mathrm{CO}_{2}$ of motor vehicle exhaust emissions in Beijing using a TDLAS system," in Optical Technologies for Atmospheric, Ocean, and Environmental Studies, vol. 5832 of Proceedings of SPIE, pp. 350-358, SPIE, Beijing, China, Aughust 2005.

[14] R. A. Margiotta, Improved vehicle speed estimation procedures for air quality and planning application [Ph.D. thesis], University of Tennessee, Knoxville,Tenn, USA, 1996.

[15] W.-D. Ueng, J.-Y. Lai, and Y.-C. Tsai, "Unconstrained and constrained curve fitting for reverse engineering," International Journal of Advanced Manufacturing Technology, vol. 33, no. 1112, pp. 1189-1203, 2007.

[16] J. Palacios and J. Luis, Understanding and quantifying motor vehicle emissions with vehicle specific power and Tildas remote sensing, [Ph.D. thesis], Department of Mechanical Engineering, Massachusetts Institute of Technology, Cambridge, Mass, USA, 1999.

[17] Y. X. Niu, M. Niu, and Y. Li, "Application of man-machineenvironment system engineering in urban road traffic safety in China," in Proceedings of the 9th Conference on Man-MachineEnvironment System Engineering (MMESE '09), pp. 282-285, Dandong, China, Aughust 2009.

[18] F. Siebel, W. Mauser, S. Moutari, and M. Rascle, "Balanced vehicular traffic at a bottleneck," Mathematical and Computer Modelling, vol. 49, no. 3-4, pp. 689-702, 2009.

[19] M. Smith and R. Mailler, "The effect of congestion frequency and saturation on coordinated traffic routing," in Agents in Principle, Agents in Practice, vol. 7047 of Lecture Notes in Artificial Intelligence, pp. 187-201, 2011.

[20] V. T. Arasan and P. Vedagiri, "Estimation of saturation flow of heterogeneous traffic using computer simulation," in Proceedings of the 20th European Conference on Modelling and Simulation: Modelling Methodologies and Simulation Key Technologies in Academia and Industry, (ECMS '06), pp. 393-398, Bonn, Germany, May 2006. 


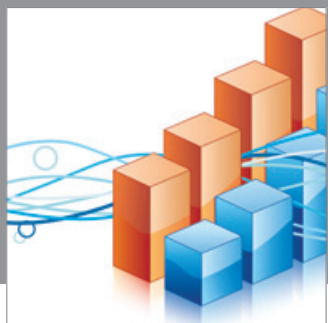

Advances in

Operations Research

mansans

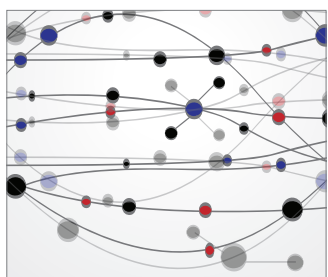

The Scientific World Journal
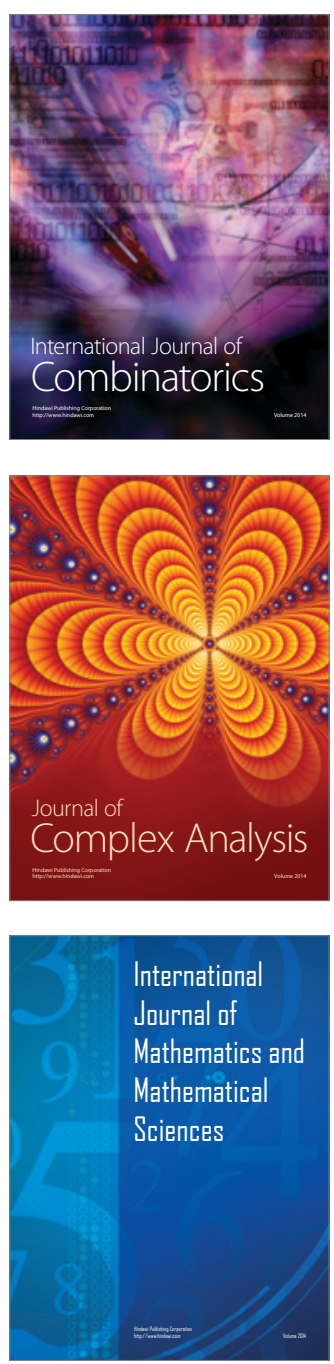
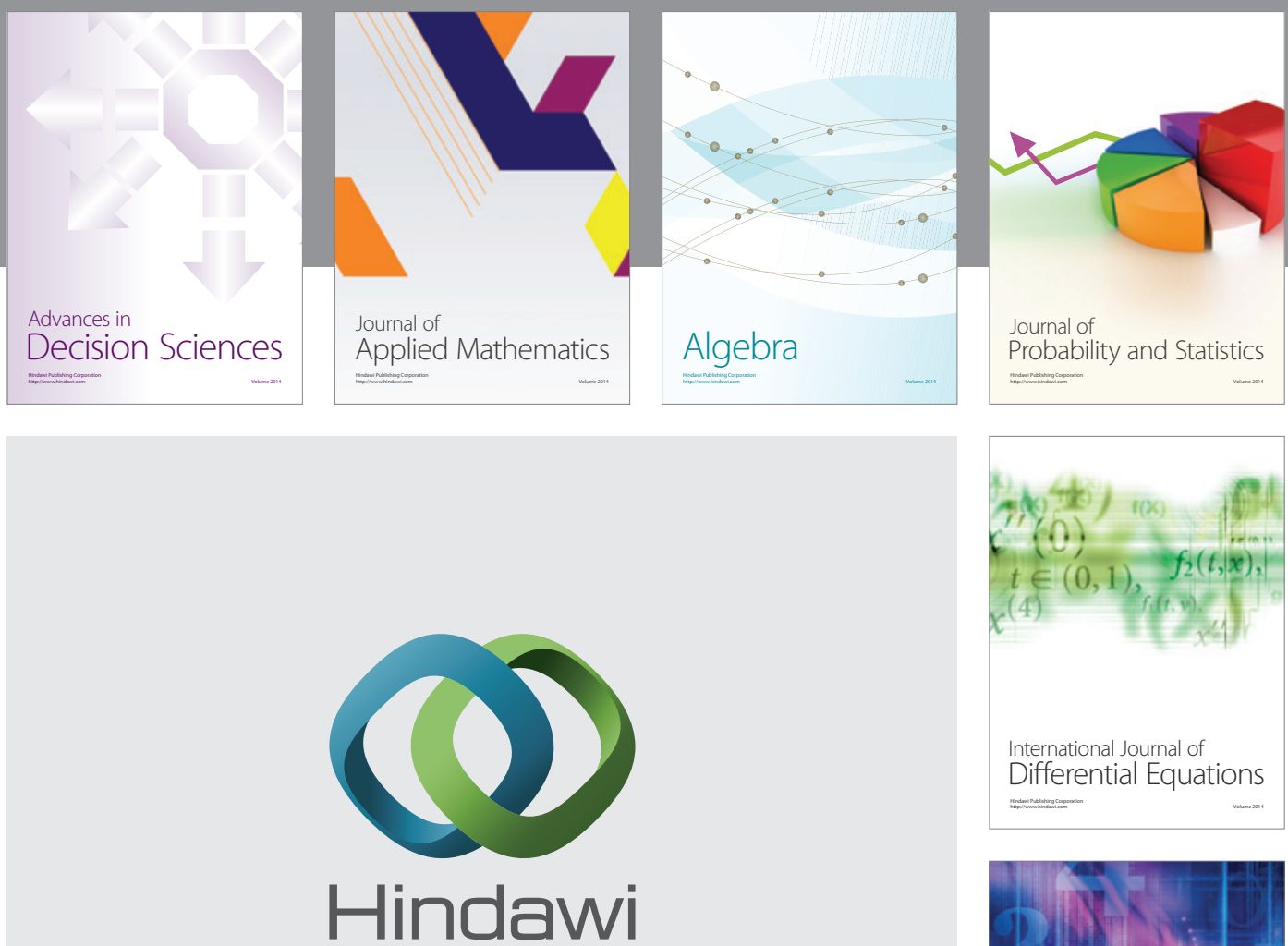

Submit your manuscripts at http://www.hindawi.com
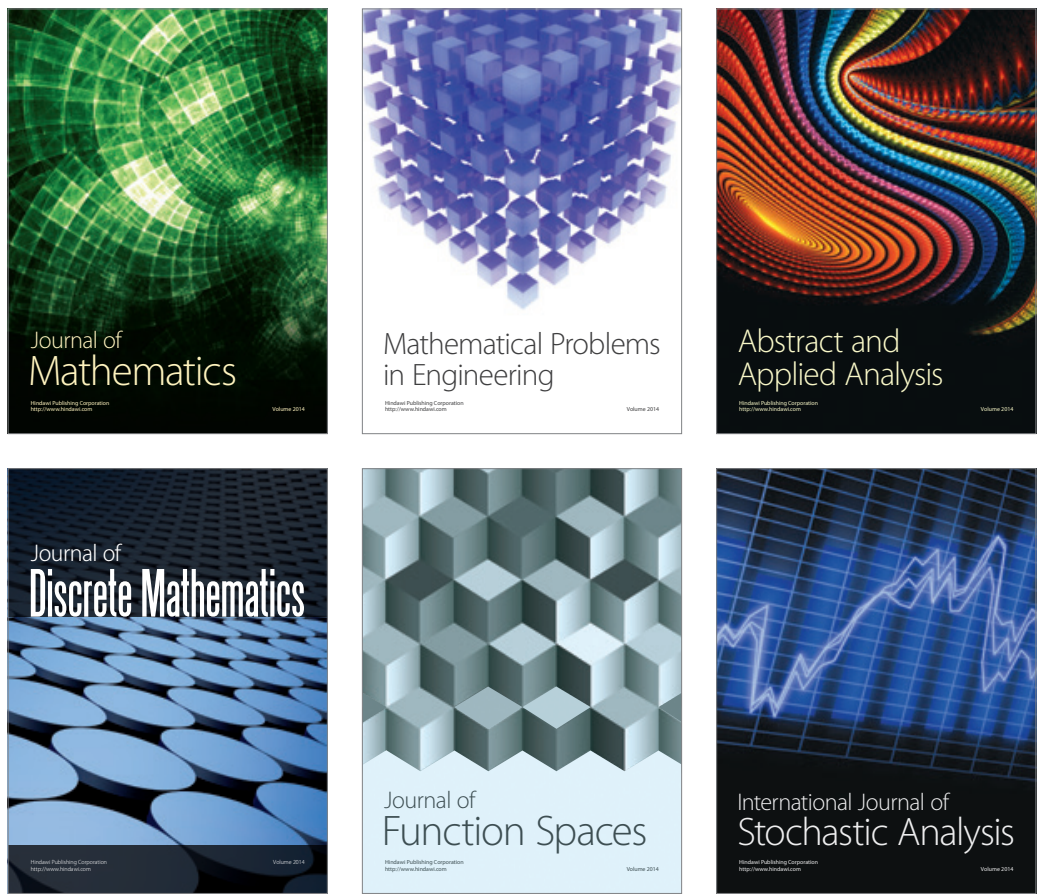

Journal of

Function Spaces

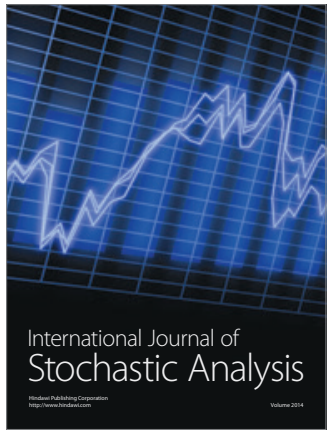

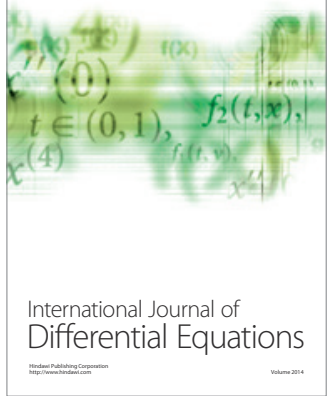
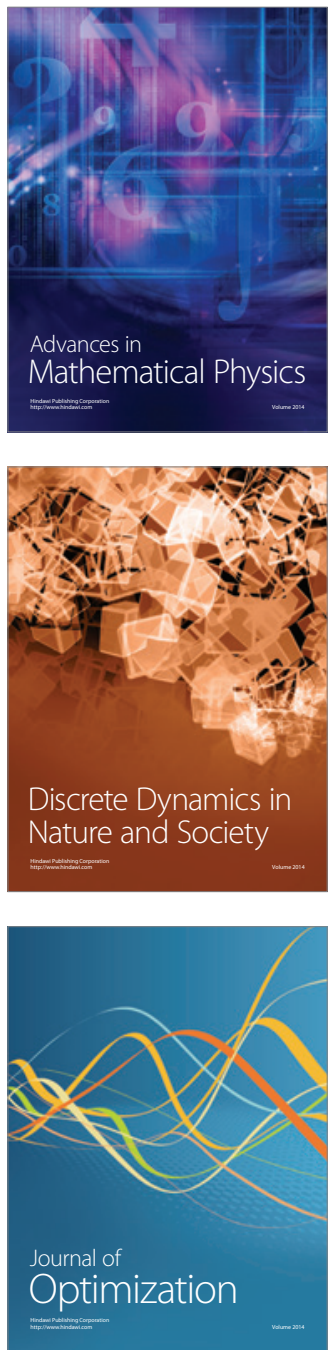